\title{
Effect of Injecting Epoxy Resin Adhesive into Cement Mortar on Tile Adhesion Performance
}

\author{
Sangkyu Lee ${ }^{1} \mathbb{D}$, Sangyun Lee ${ }^{2}$, Gyuyong Kim ${ }^{1, * \mathbb{C}}$, Minjae Son ${ }^{1}$, Gyeongcheol Choe ${ }^{1}$, \\ Jaehyun Lee ${ }^{3}$ iD and Jeongsoo Nam ${ }^{1}$ \\ 1 Department of Architectural Engineering, Chungnam National University, 99 Daehak-ro, Yuseong-gu, \\ Daejeon 34134, Korea; lsg2357@naver.com (S.L.); minjae931226@naver.com (M.S.); choegc@cnu.ac.kr (G.C.); \\ j.nam@cnu.ac.kr (J.N.) \\ 2 Korea Environment Industry, 46-8, 3 Mannyeonnam-ro, Seo-gu, Daejeon 35200, Korea; sy1246@hanmail.net \\ 3 Department of Safety Engineering, Seoul National University of Science and Technology, 232 Gongneung-ro, \\ Nowon-gu, Seoul 01811, Korea; archi0528@seoultech.ac.kr \\ * Correspondence: gyuyongkim@cnu.ac.kr; Tel.: +82-42-821-5623
}

Received: 8 November 2020; Accepted: 26 November 2020; Published: 28 November 2020

\begin{abstract}
Large porcelain tiles have attracted increased demand owing to their cost-effectiveness and superior esthetics. Here, an epoxy resin adhesive was injected into cement mortar, which was then applied to tiles. The adhesion performance of the tiles was subsequently evaluated in terms of the permeability and drying shrinkage under various curing conditions. The epoxy resin adhesive not only penetrated the tile-mortar and mortar-concrete interfaces, but also directly penetrated the mortar, thus enhancing the mechanical adhesion at each interface. In addition to the mechanical adhesion between the tiles and mortar, the epoxy resin adhesive prevents the degradation of adhesion due to shear stress by minimizing the moisture evaporation and shrinkage of the mortar. Evaluation of the adhesion characteristics under water and freeze-thaw curing conditions revealed the vulnerability of the epoxy resin to moisture; however, adequate adhesion performance was observed when the epoxy resin was air-cured prior to being exposed to harsh environments. Moreover, the injection method did not prolong the construction period, but could potentially reduce it during actual application. Nevertheless, further research on the adhesion performance of tiles with injected epoxy resin adhesive is required to evaluate the long-term durability.
\end{abstract}

Keywords: epoxy resin; injection; tile; cement mortar

\section{Introduction}

The increased construction of large buildings and burgeoning interest in interior and exterior designs have fostered a shift in the demand for small ceramic tiles to large esthetically appealing porcelain tiles. Conventional ceramic tiles are porous and exhibit a high absorption rate. However, superior adhesion performance is achieved through mechanical fixation when cement hydrate is deposited within the pores [1,2]. In contrast, porcelain tiles are fouling-resistant and are less susceptible to damage from moisture expansion and freezing due to the existence of minute pores, which make them essentially nonporous compared to ceramic tiles [2-4]. Unfortunately, the minute pores of porcelain tiles result in a smooth rear surface, thereby making it difficult to achieve strong adhesion of the tiles using ordinary mortar $[2,5]$.

Therefore, plastering techniques using polymer-based adhesives are being extensively adopted in many countries to enhance the adhesion performance of porcelain tiles. However, the use of dry cement mortar and bedding techniques remains popular because surface finishing is often omitted in many countries, including South Korea, due to economic reasons. Various polymer-based adhesives 
are applied, some of which are not used judiciously. Consequently, the adhesion and internal strengths of the adhesives are considerably reduced, resulting in delayed curing, contraction, and expansion of the adhesives, which negatively impact the construction quality.

In fact, according to the National Assembly's Transportation Committee in South Korea, tile defects have accounted for the largest proportion (34.5\%) of defects in the apartment construction of Company A over a period of three years (2015 to 2017). Further, the number of international cases of floor and wall tile failures has also been increasing [6-8]. Tile defects can cause the tiles to fall off within living and working spaces, thus raising safety concerns for individuals. Moreover, the additional costs of demolition and reconstruction increase the economic losses, and considerable construction waste is generated, along with noise and scattering dust when the tiles are dismantled, thus resulting in inconvenience and negative environmental impact. Therefore, it is necessary to achieve an improved tile with more reliable adhesion performance during construction.

Previous studies have reported that the application of cement-type adhesive mortar (e.g., dry cement mortar) to large-sized tiles can cause cracks as a result of the concentrated stress owing to changes in the volume during shrinkage and expansion $[9,10]$. To mitigate this type of construction defect, epoxy resin was used in this study. In addition to the advantages of high adhesion strength and low shrinkage, Ohama et al. postulated that epoxy resin cures through chemical adhesion with cement mortar, and provides restorative effects by penetrating and curing within the cracks $[11,12]$. These advantages of epoxy resin are expected to be particularly beneficial in constructions that utilize dry cement mortar as the tile adhesive.

Herein, we review the applicability of the proposed method of injecting an epoxy resin adhesive between the tile joints (Figure 1) during the conventional curing process, without extending the construction period (Figure 2). Further, the bisphenol A-type epoxy resin was utilized and the viscosity and permeability at various solvent mixing ratios increased the workability and adhesion efficiency by injecting the epoxy resin. Subsequently, the mechanical and dry shrinkage properties of the selected epoxy resin adhesive were confirmed based on the penetration results, and the adhesion performance of the tiles was evaluated.
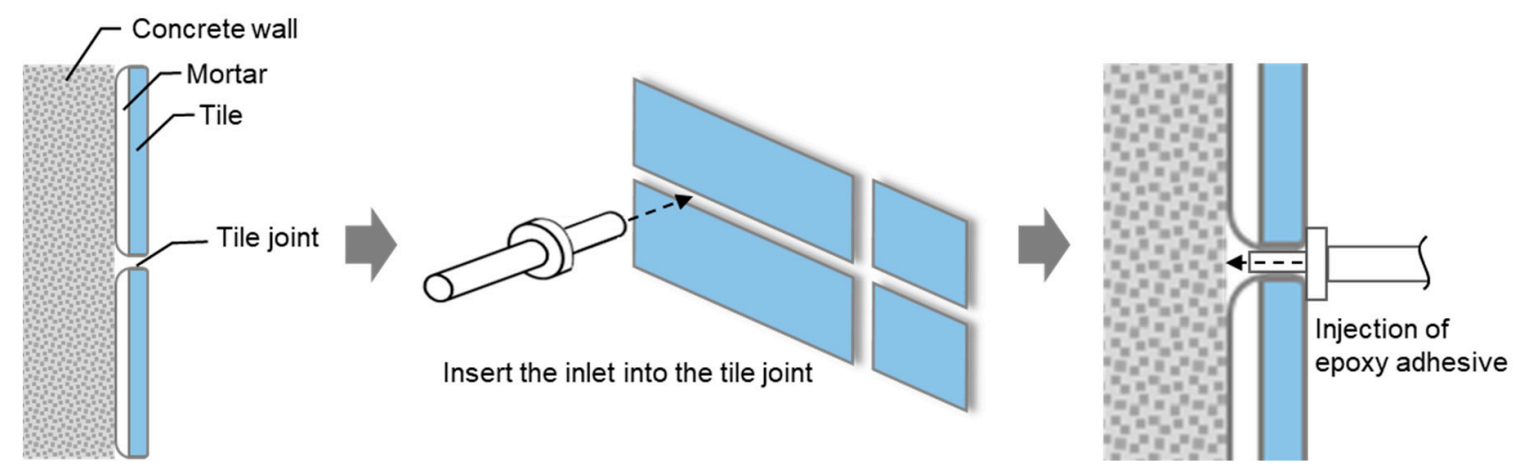

Figure 1. Outline of epoxy resin injection for reinforcement.

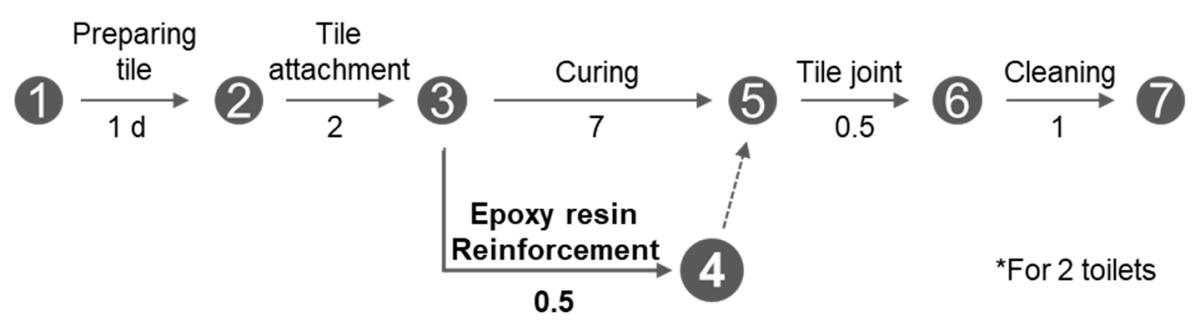

Figure 2. Process of epoxy resin reinforcement. 


\section{Materials and Methods}

\subsection{Materials and Mixture Proportions}

Epoxy resin comprising diglycidyl ether of bisphenol A (DGEBA, 189 g/eq, 11,500 cps) as the primary ingredient and a curing agent comprising amino amine as the main ingredient was used. Both the epoxy resin and the curing agent were purchased from Epoxy Industrial Co. (Incheon, Korea). A xylene-type solvent was purchased from GS Caltex (Seoul, Korea).

The epoxy resin and the curing agent were mixed in a 2:1 ratio. Various solvent mixing ratios $(0,5,10$, and $15 \mathrm{wt} \%)$ were used to evaluate the penetration; based on the evaluation result, $5 \mathrm{wt} \%$ solvent was used for subsequent studies. Dry ready-mixed cement (DM) and adhesive (AM) mortars, which are popular in South Korea, were used; their compositions are listed in Table 1. AM and DM were mixed with water in a 5:1 ratio. Commercial ceramic, porcelain, and polished tiles suitable for KS (Korean Industrial Standards) L 1001 were used.

Table 1. Composition of the tile mortar (in wt $\%$ ).

\begin{tabular}{llc}
\hline Materials & DM & AM \\
\hline Portland cement & 17 & 20 \\
Quartz sand 0.3-0.9 mm & 20 & \\
Quartz sand 0.1-0.6 mm & 60 & 40 \\
Quartz sand 0.1-0.3 mm & & 30 \\
Dolomite filler & 3 & 6 \\
Redispersible polymer powder & - & 4 \\
\hline
\end{tabular}

\subsection{Experimental Plan and Test Methodology}

Table 2 depicts the experimental plan. The viscosity, curing time, and penetration depth were evaluated using mortar bars, and the permeability was evaluated by a full-scale mockup test to identify the workability and permeability of the epoxy resin adhesive. The viscosity of the epoxy adhesive was measured using a DV2T Touch Screen Viscometer (USA) in accordance with KS M ISO 3219, and the curing time was measured based on the set-to-touch time. The curing time was measured by preparing the epoxy resin with the solvent at various mixing ratios and placing in a mold $(150 \times 75 \times 1 \mathrm{~mm})$. The curing process was observed at $5 \mathrm{~min}$ intervals $30 \mathrm{~min}$ after the start of curing at constant temperature $\left(25 \pm 5{ }^{\circ} \mathrm{C}\right)$ and humidity $(50 \pm 5 \%)$.

Table 2. Experimental plan.

\begin{tabular}{|c|c|c|}
\hline Evaluation Item & Adhesive Used $^{1}$ & Tile Used \\
\hline $\begin{array}{l}\text { Viscosity of the epoxy resin adhesive } \\
\text { Setting time of the epoxy resin adhesive } \\
\text { Permeability of the epoxy resin adhesive }\end{array}$ & $\begin{array}{c}\text { Epoxy resin adhesive } \\
\text { (solvent: } 0,5,10,15 \mathrm{wt} \% \text { ) }\end{array}$ & - \\
\hline \multicolumn{3}{|l|}{ Flexural and compressive strength of the mortar } \\
\hline Shrinkage of the mortar and tile & $\begin{array}{c}\text { DM } \\
\text { AM } \\
\text { ERM } \\
\text { (solvent: } 5 w t \% \text { ) }\end{array}$ & $\begin{array}{c}\text { Ceramic tile } \\
\text { (water absorption } \leq 10 \% \text { ) } \\
\text { Porcelain tile } \\
\text { (water absorption } \leq 0.5 \% \text { ) } \\
\text { Polished tile } \\
\text { (water absorption } \leq 0.2 \% \text { ) }\end{array}$ \\
\hline
\end{tabular}

${ }^{1}$ DM: dry ready-mixed cement mortar, AM: adhesive mortar, ERM: epoxy reinforced DM.

The permeability of the epoxy adhesive was evaluated by producing a mortar bar $(40 \times 40 \times 160 \mathrm{~mm})$ using DM and attaching a film, as illustrated in Figure 3. The epoxy adhesive was subsequently applied to the top of the mortar bar and maintained for $20 \mathrm{~min}$. After $20 \mathrm{~min}$, the mortar bar was cut and the penetration depth of the epoxy adhesive was measured. The full-scale mockup was performed 
by applying DM on a wall, as shown in Figure 4, and curing it with an acrylic panel placed on the top. Urethane foam was applied to each tile joint to prevent the epoxy adhesive injected at the top from rapidly flowing to the bottom and reducing the permeability. The penetration of the epoxy resin in the mortar was observed by visual inspection. Additionally, scanning electron microscopy was conducted on the resulting specimens to analyze the penetration of the adhesive in the mortar.

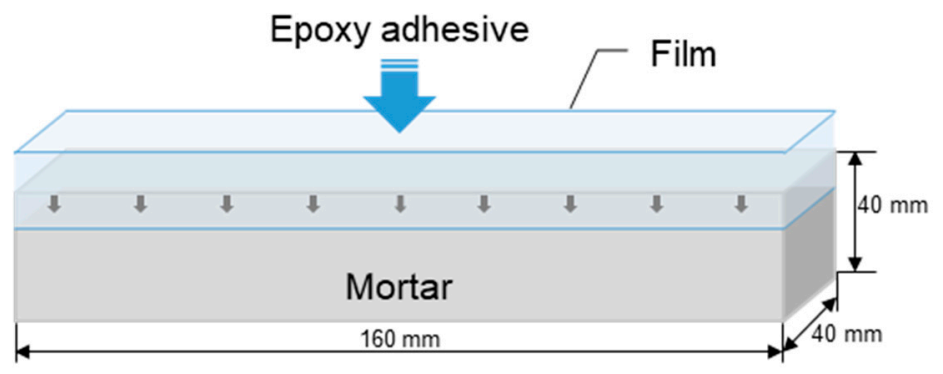

Figure 3. Test method for permeability of the epoxy resin adhesive.
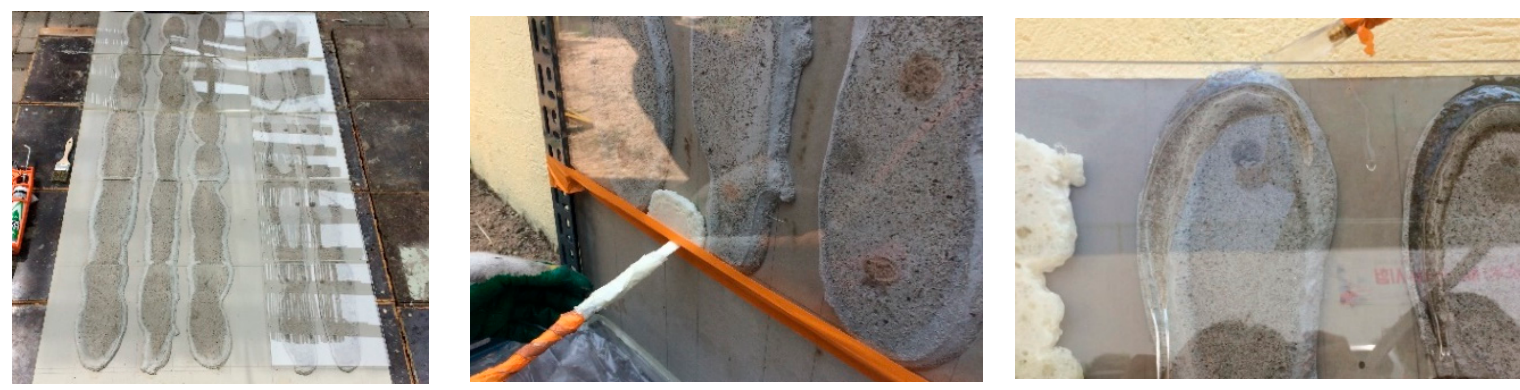

Figure 4. Test method for the permeability of the epoxy resin adhesive (mockup).

To identify the mechanical properties of the mortar after reinforcement with the epoxy adhesive, mortar bars $(40 \times 40 \times 160 \mathrm{~mm})$ were manufactured using DM, AM, and epoxy reinforced DM (ERM), and the flexural and compressive strengths were measured in accordance with KS L ISO 679. The flexural and compressive strengths were determined using loading rates of $50 \pm 10 \mathrm{~N} / \mathrm{s}$ and $2400 \pm 200 \mathrm{~N} / \mathrm{s}$, respectively. The shrinkage properties of the tiles and mortar were evaluated using the method shown in Figure 5. Both the tiles and mortar were measured for approximately 1 month after curing for 7 days.
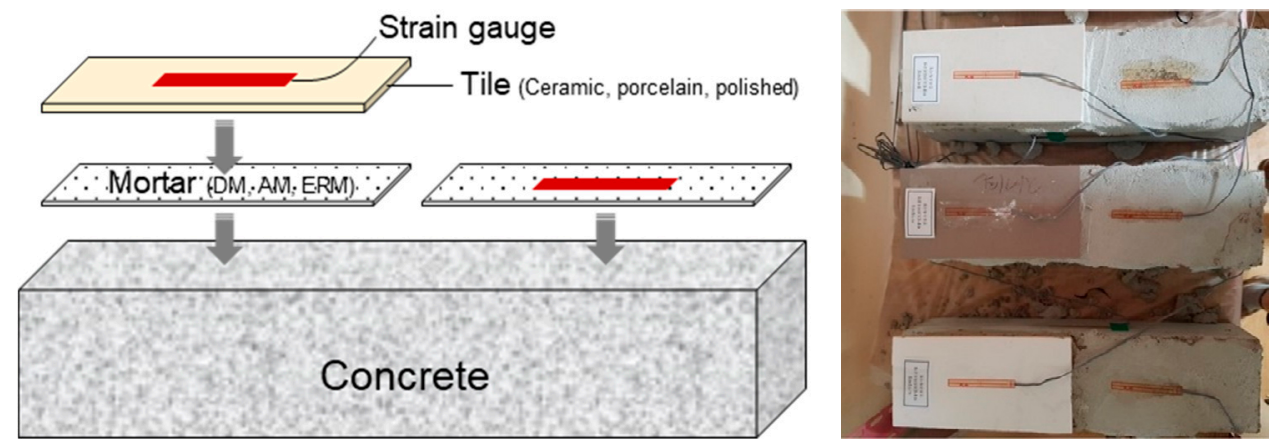

Figure 5. Test method for the shrinkage of mortar and tile.

To evaluate the adhesion performance of the tiles reinforced with epoxy adhesive, the adhesion strengths under air curing, water curing, freeze-thawing, and salt immersion conditions were measured in accordance with EN 12004. The details of each experiment environment were as follows: 
1. Air curing: standard condition for $28 \mathrm{~d}\left(23 \pm 2{ }^{\circ} \mathrm{C}, 50 \pm 5 \% \mathrm{RH}\right)$.

2. Water curing: standard condition for $7 \mathrm{~d}$ and water curing for $21 \mathrm{~d}\left(20 \pm 2{ }^{\circ} \mathrm{C}\right)$.

3. Freeze-thawing: standard condition for $7 \mathrm{~d}$, water curing for $21 \mathrm{~d}$ and 25 cycles of freeze-thawing $\left(-15 \pm 3^{\circ} \mathrm{C}, 15 \pm 3^{\circ} \mathrm{C}\right.$ for $2 \mathrm{~h} \pm 20 \mathrm{~min}$, respectively).

4. Salt immersion: standard condition for $28 \mathrm{~d}$, immersion in chlorinated water (chlorine content: 0.3 0.6 mg/L, pH value: 6.5 7.8) for $7 \mathrm{~d}$, rinse with clean tap water, standard condition for $24 \mathrm{~h}$.

Additionally, the adhesion strength was assessed in the presence and absence of laitance to account for the actual site conditions.

\section{Results and Discussion}

\subsection{Permeability of Epoxy Resin into Mortar}

Figure 6 shows the viscosity and setting time of the epoxy resin adhesive at various solvent mixing ratios. The viscosity was drastically reduced to $2820 \mathrm{cps}$ when the solvent was mixed at $5 \mathrm{wt} \%$, whereas the highest fluidity (170 cps) was achieved when the solvent was mixed at $15 \mathrm{wt} \%$. However, the workability was presumably low at a solvent mixing ratio of $15 \mathrm{wt} \%$ during the injection of the epoxy resin adhesive because the viscosity was similar to that of water. The setting times with no solvent (91.5 and $110.3 \mathrm{~min}$ ) differed by $18.8 \mathrm{~min}$ when the solvent ratio was $15 \mathrm{wt} \%$. Within the range of mixing ratios used in this study, the effect of the solvent on the setting time was smaller than that on the viscosity.

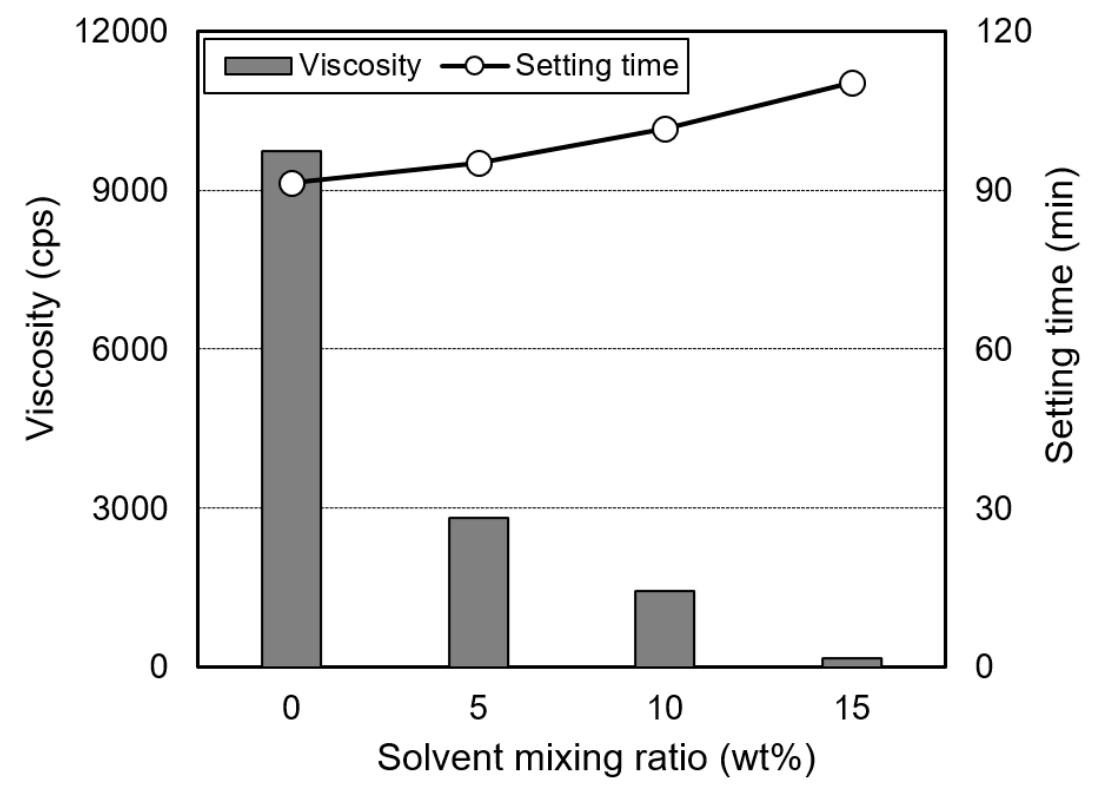

Figure 6. Viscosity and setting time of epoxy resin based on the solvent mixing ratio.

Figure 7 depicts the penetration depth of the epoxy resin adhesive in relation to the solvent mixing ratio. The penetration depth was approximately $1.31 \mathrm{~mm}$ in the absence of solvent; however, it increased drastically to $5.3 \mathrm{~mm}$ when the solvent ratio was $5 \mathrm{wt} \%$. A further increase in the penetration depth to $6.59 \mathrm{~mm}$ at a $15 \mathrm{wt} \%$ solvent mixing ratio confirmed that the penetration depth of the epoxy resin adhesive increased with increasing solvent mixing ratio. 


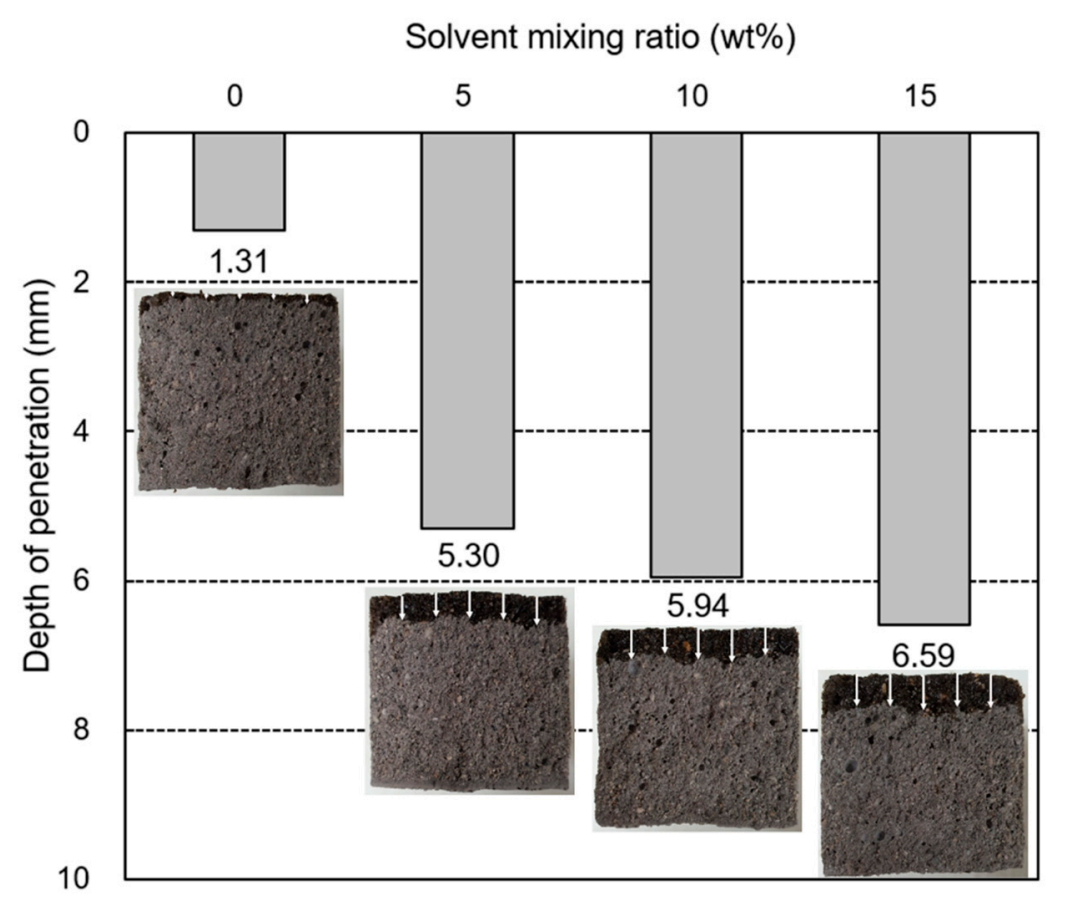

Figure 7. Penetration depth of epoxy resin based on the solvent mixing ratio.

Figure 8 shows the result of the mockup test in which the epoxy resin adhesive was injected at the tile joint at the top of a tile to evaluate the permeability of the adhesive as a function of the solvent mixing ratio. Contrary to the results of the test conducted using mortar bars, the mockup test confirmed that the optimum and lowest permeabilities were achieved when the adhesive contained 5 and $15 \mathrm{wt} \%$ solvent, respectively. The adhesive containing $5 \mathrm{wt} \%$ solvent was more viscous than those containing 10 and $15 \mathrm{wt} \%$; therefore, the former took longer to move from the top to the bottom of the mortar, with more gradual penetration. In the case of the adhesive containing $15 \mathrm{wt} \%$ solvent, the reinforcement injected at the top traveled rapidly towards the bottom, resulting in insufficient time for penetration to occur. Hence, the adhesive was absorbed faster by the urethane foam than by the mortar at the bottom, thereby reducing the amount of the reinforcement penetrating the mortar. This result suggested that, for the injection method, the permeability of the epoxy resin adhesive should be carefully considered and that the solvent mixing ratio of $5 \mathrm{wt} \%$ provided the most effective penetration of the epoxy resin adhesive. 

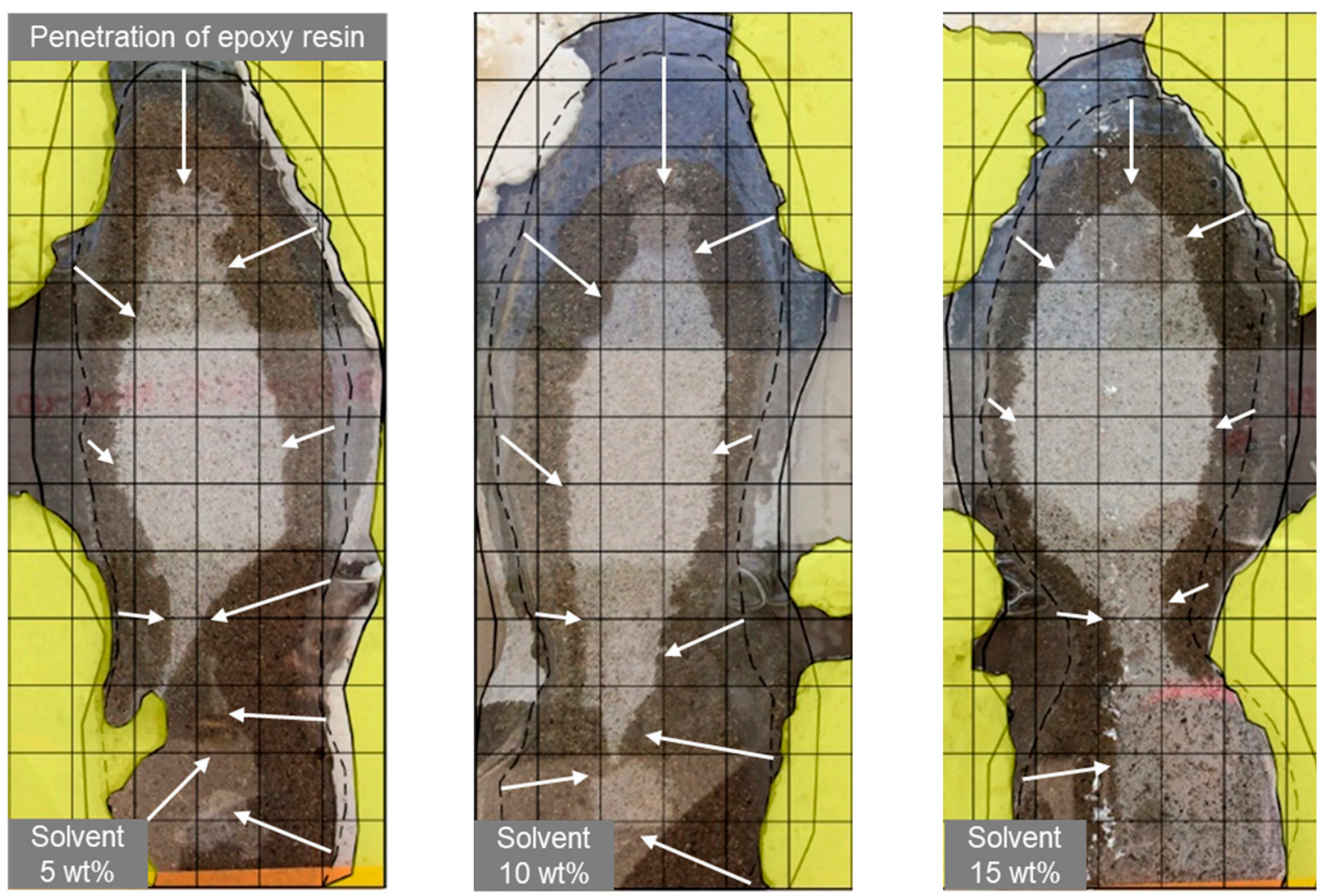

Figure 8. Permeability of epoxy resin based on the solvent mixing ratio.

\subsection{Mechanical Properties}

Figure 9 shows the flexural and compressive strengths with different types of tile mortar. The average flexural strength of the ERM was $4.08 \mathrm{MPa}$. This indicated that the ERM demonstrated the highest flexural and compressive strengths compared to those of the widely used DM and AM. As shown in Figure 10, the epoxy resin adhesive improved the flexural tensile performance and resistance to lateral loads by penetrating and curing inside the pores of the mortar, thus significantly increasing the flexural and compressive strengths.

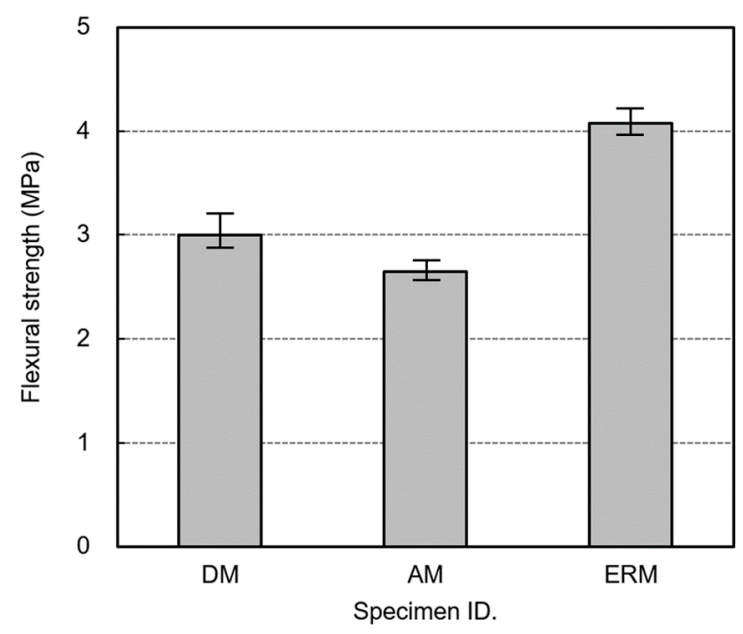

(a)

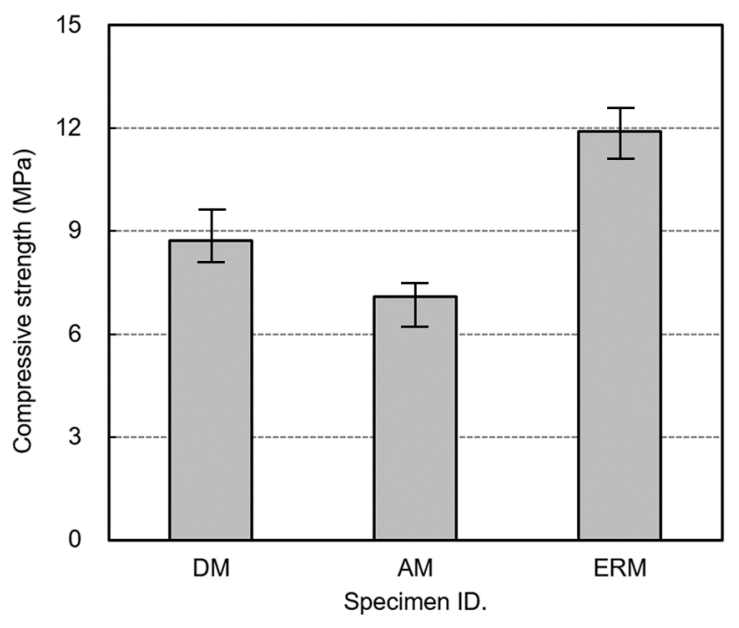

(b)

Figure 9. (a) Flexural and (b) compressive strength based on the mortar type. 


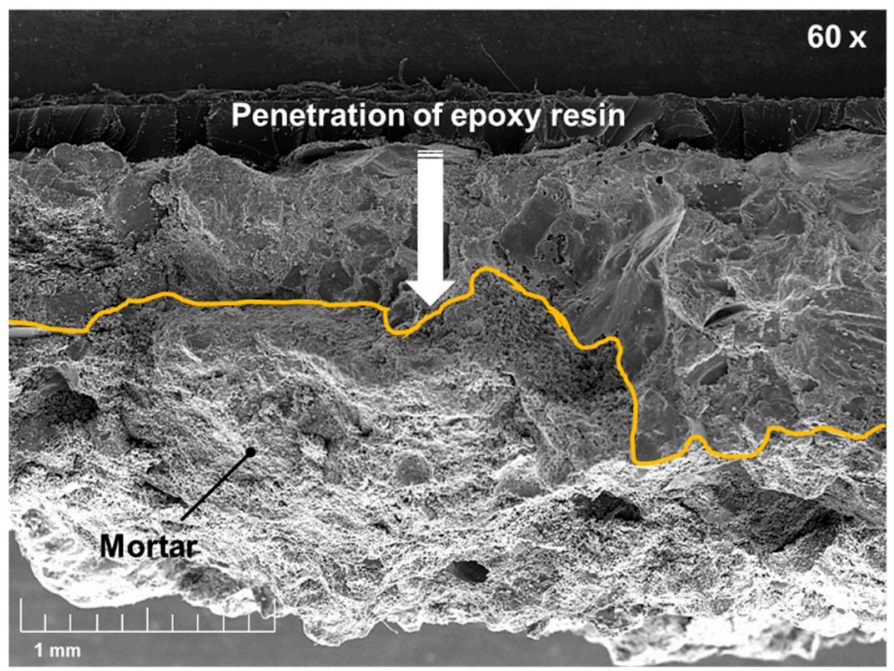

(a)

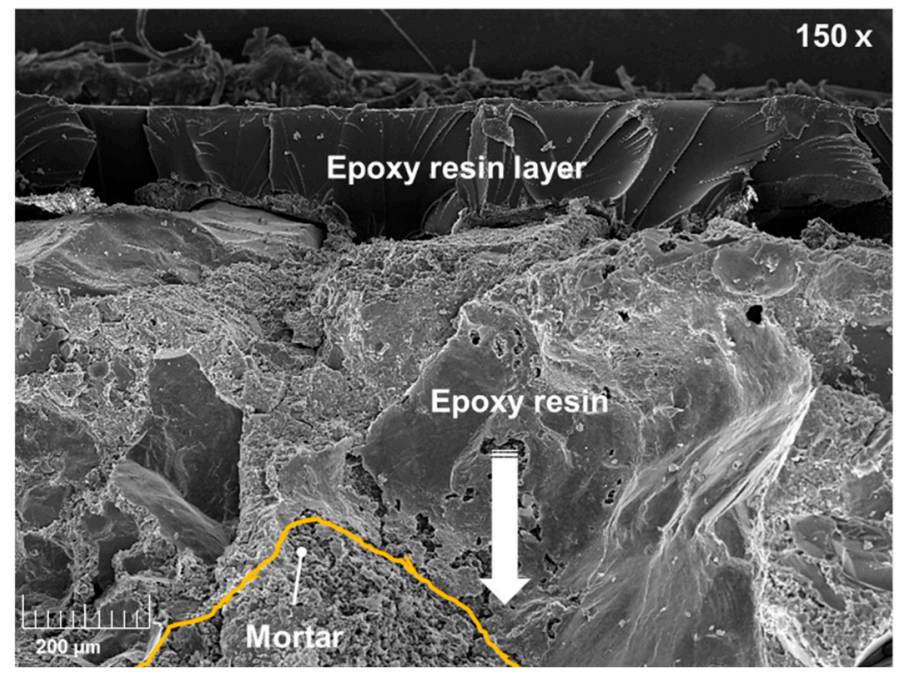

(b)

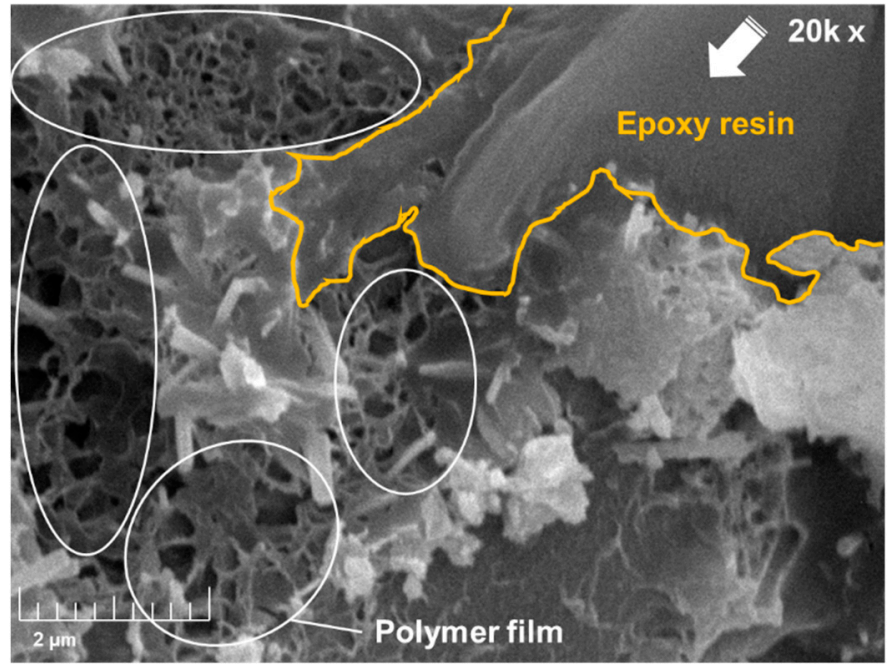

(c)

Figure 10. Penetration status of epoxy resin inside the mortar: (a) $60 \times$, (b) $150 \times$, and (c) $20 \mathrm{k} \times$. 
In particular, previous studies have postulated that the epoxy resin transformed into polymer films (i.e., telechelic polymers) and combined with a cement matrix to achieve enhanced strength $[13,14]$. Here, we confirmed the structure of the telechelic polymer, which may be linked to the strength enhancement.

Moreover, the microstructural analysis directly confirmed the degree of penetration of the epoxy resin adhesive that had been previously visually inspected.

\subsection{Shrinkage Characteristics}

Figure 11 depicts the drying shrinkage strain of the actual mortar. In the case of DM, the continuous hydration reaction and evaporation of moisture resulted in the largest drying shrinkage strain. The drying shrinkage strain of AM, which is a mixture of mortar cement and a polymer-type ingredient, was smaller than that of DM because of the reduced bleeding and improved cement cohesion produced by the addition of the polymer [15-17]. Meanwhile, ERM exhibited a smaller drying shrinkage strain than DM and AM. This is attributed to reduced moisture evaporation from the mortar with the epoxy resin adhesive and the suppressed shrinkage as the epoxy resin reinforcement penetrated and cured inside the mortar matrix.

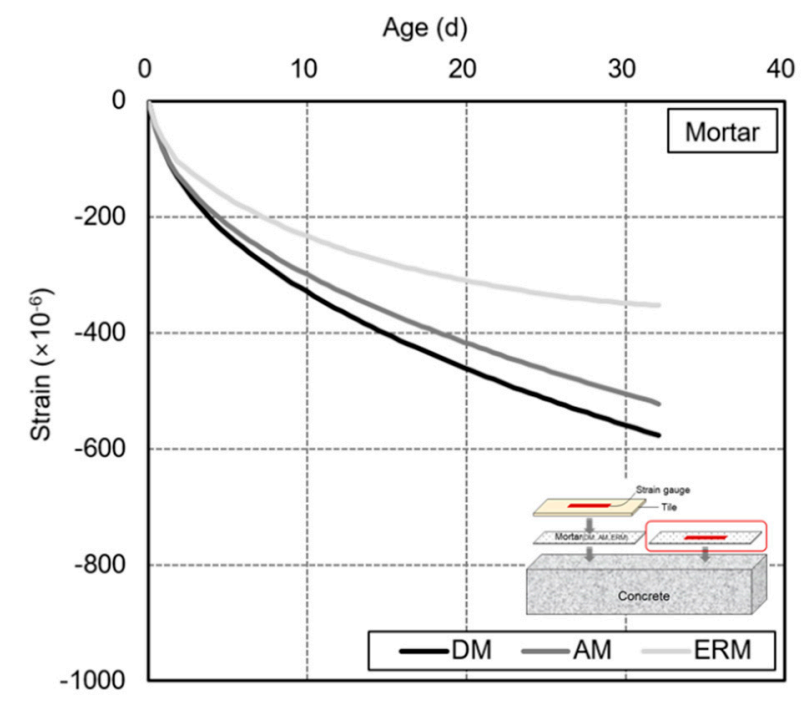

Figure 11. Drying shrinkage of mortar.

Figure 12 shows the shrinkage strain of the tile surface as a function of the type of tile. The shrinkage strain was lowest for all tiles when the epoxy resin adhesive was used; this was particularly evident with the ceramic tile. Furthermore, compared to the other specimens, the shrinkage stabilized more quickly when the epoxy resin reinforcement was used, regardless of the type of tile. The ceramic tile was most impacted by shrinkage because the tile itself exhibited high porosity and absorption compared to the porcelain and polished tiles. The low porosity and absorption rate of the porcelain and polished tiles resulted in less shrinkage, which was even more pronounced when ERM was used. Previous studies have reported that the occurrence of shear stress due to the drying and hydration shrinkages of the mortar is an important factor in reducing the adhesion of the tiles and mortar $[9,10,18]$. The smaller shrinkage observed with the use of ERM is expected to effectively enhance the adhesion strength. 


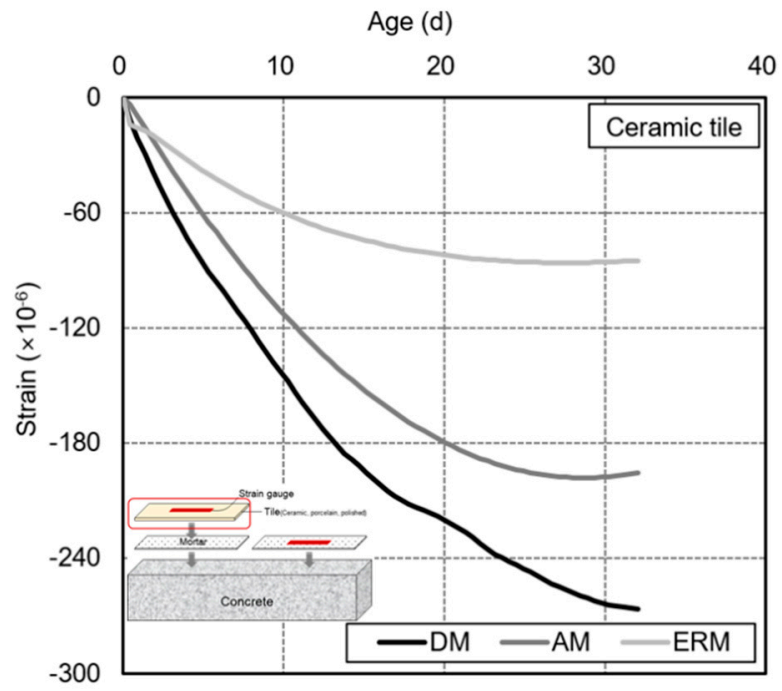

(a)

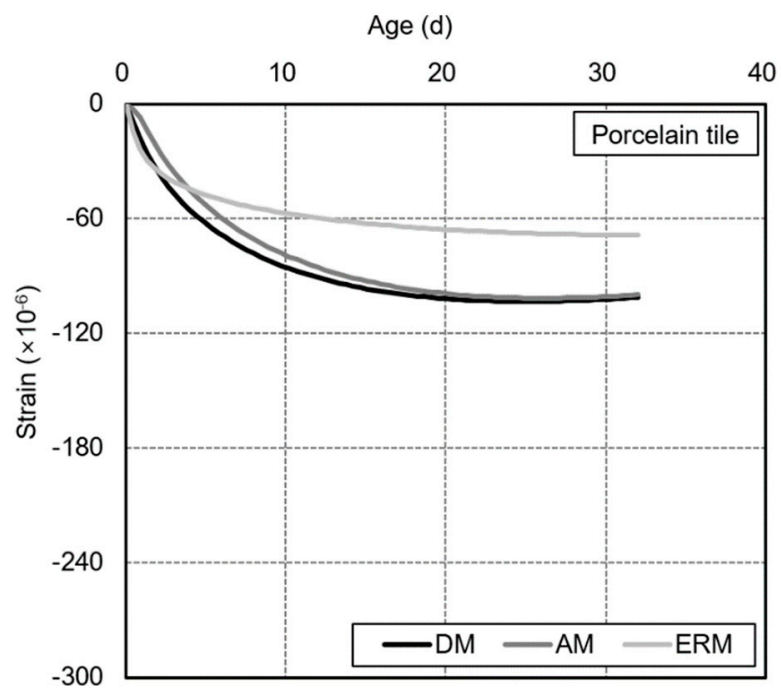

(b)

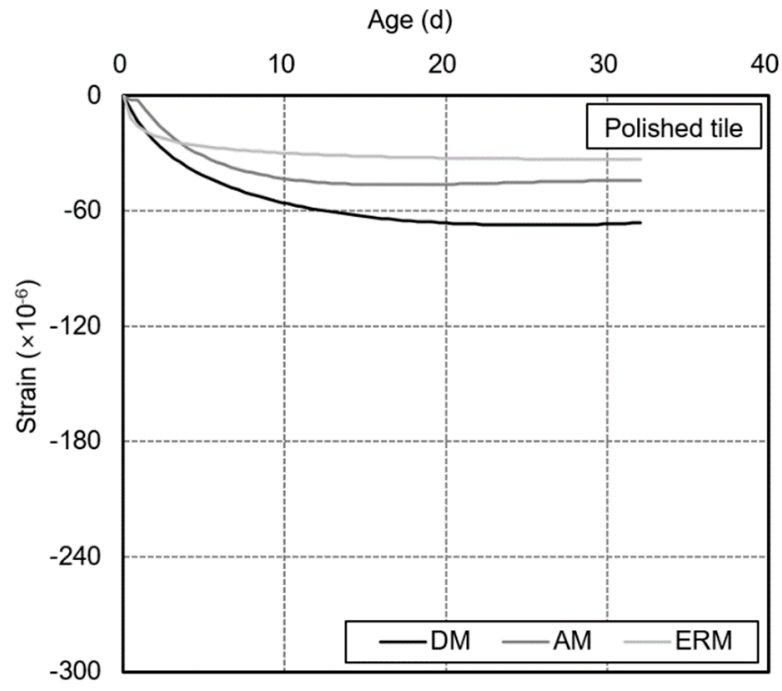

(c)

Figure 12. Shrinkage of tile: (a) ceramic, (b) porcelain, and (c) polished. 


\subsection{Adhesive Strength of Tile with Epoxy Resin Injection Reinforcement}

Figure 13 shows the adhesion strength based on the curing conditions. As seen in Figure 13a, under standard air curing conditions, the specimens with the epoxy resin adhesive exhibited the highest adhesion strength, regardless of the type of tile. This may be because the formation and dispersion of a polymer film based on the penetration of the epoxy resin into the cement matrix improves the bonding strength $[19,20]$. The adhesion strengths of the porcelain and polished tiles were lower because of their small pore sizes and absorption rates, making it difficult for the mortar to penetrate and mechanically adhere to the tiles. Figure $13 \mathrm{~b}$ shows the adhesion strength under water curing conditions. In comparison to air curing, the adhesion strength of DM and AM improved significantly with water curing, owing to the reduced moisture evaporation and stable hydration reaction. However, ERM demonstrated a lower adhesion strength than the other specimens when air-cured. This is presumably due to the mechanical degradation of the epoxy as it absorbs water, which also reduces the adhesion strength. Previous reports have also confirmed the degradation of the mechanical properties of epoxy, such as the tensile strength and elastic modulus, due to water absorption and the plasticization effect [21-23]. Figure 13c shows the adhesion strength under freezing-thawing conditions. Overall, the adhesion strength under freezing-thawing conditions was lower than that under water curing conditions. In particular, the adhesion strength of ERM was reduced as a result of the water curing performed prior to freezing-thawing and the stress caused by the different linear expansion coefficients of the epoxy resin adhesive and mortar.

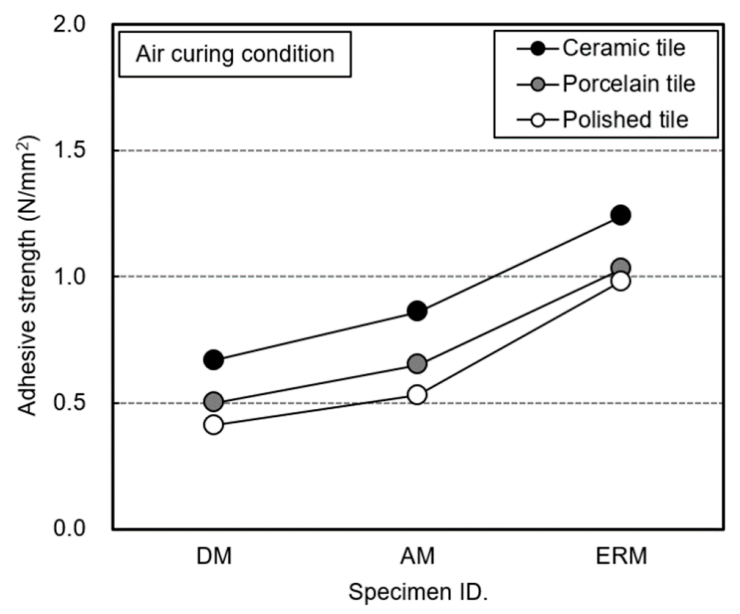

(a)

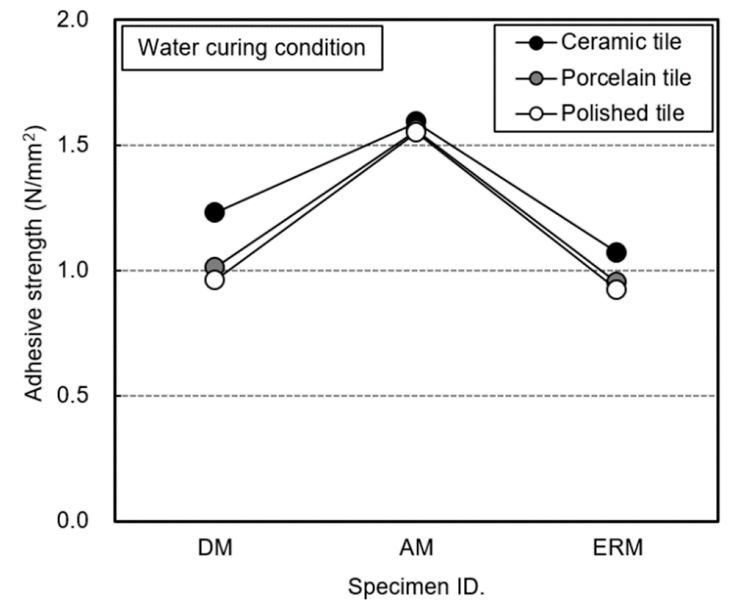

(b)

Figure 13. Cont. 


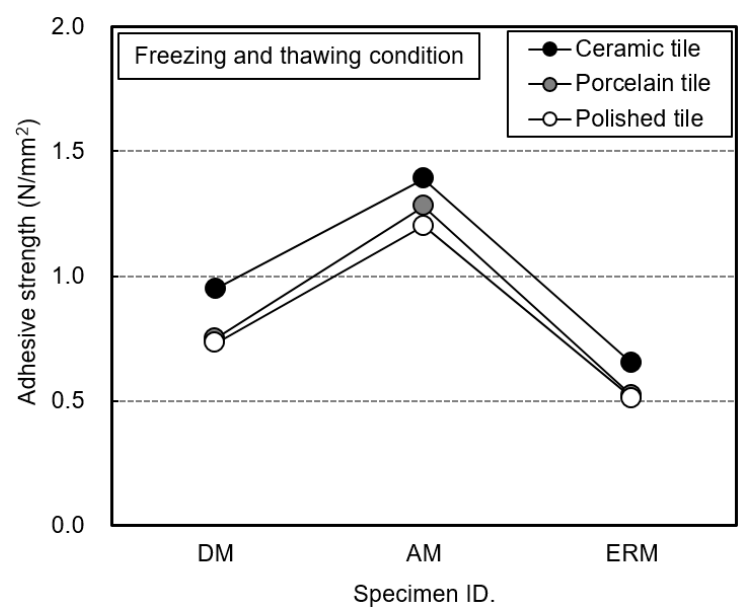

(c)

Figure 13. Adhesive strength based on different curing conditions: (a) air, (b) water, and (c) freezing-thawing.

Figure 14 shows the effect of salt immersion on the adhesion strength of porcelain tiles. The adhesion strengths of the tiles after salt immersion were 51, 24, and 16\% lower for DM, AM, and ERM, respectively. The penetration of chlorides supposedly reduced the durability of the DM and AM specimens and impacted the adhesion performance. Conversely, in the case of ERM, the epoxy resin functioned as a coating agent for the mortar, thus minimizing the loss of durability due to chloride penetration; however, the adhesion strength still decreased as a result of the moisture degradation of the epoxy itself.

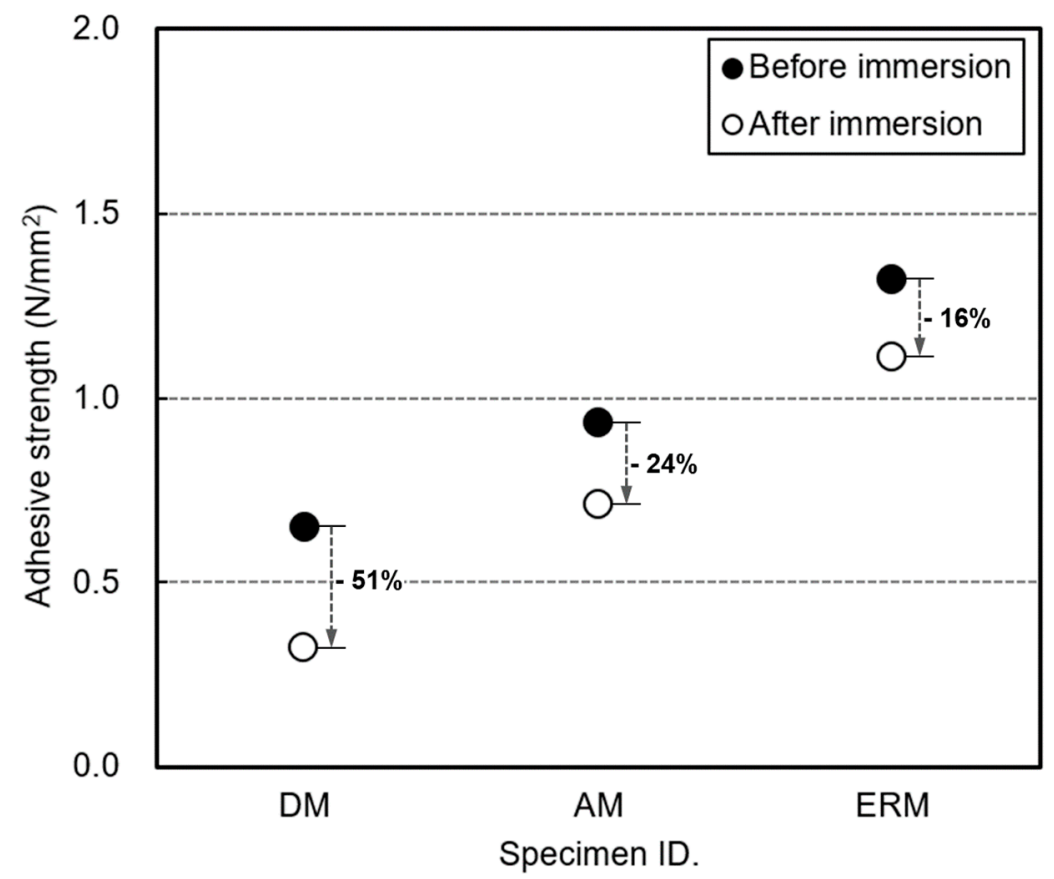

Figure 14. Adhesive strength of porcelain tile by salt immersion. 
Figure 15 shows the adhesion strength of the porcelain tiles before and after the removal of laitance. The adhesion strength before the removal of laitance was lower than that after the removal, regardless of the type of mortar. The use of ERM improved the adhesion strength by approximately 96 and 49\% compared to that of DM and AM, respectively, prior to laitance removal. The adhesion strength of ERM prior to laitance removal still exceeded those of the DM and AM specimens following laitance removal. This is attributed to the direct effect of the epoxy reinforcement after penetrating the mortar and reaching the cement interface. The results of the laitance removal indicated that ERM improved the adhesion strength by $\sim 65$ and $27 \%$ relative to DM and AM, respectively. ERM produced excellent adhesion strength, regardless of whether laitance was removed, thus demonstrating its superior adhesion. Details of the adhesive strength based on curing conditions, salt immersion and laitance are shown in Table 3.

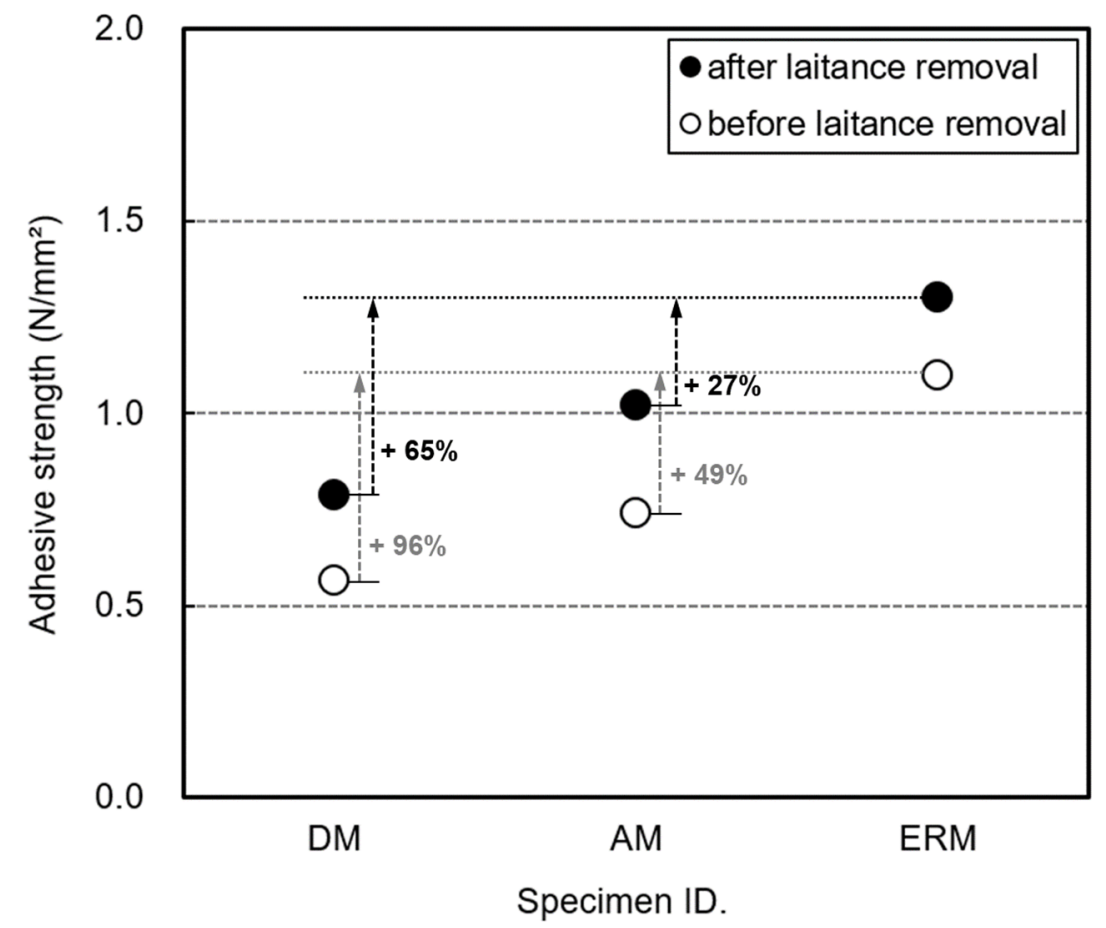

Figure 15. Adhesive strength of the porcelain tiles based on the laitance of concrete. 
Table 3. Details of adhesive strength.

\begin{tabular}{|c|c|c|c|c|c|c|c|c|c|c|c|c|c|}
\hline \multirow{3}{*}{ ID. } & \multicolumn{13}{|c|}{ Adhesive Strength Based on Curing Conditions, Salt Immersion and Laitance (N/mm²) } \\
\hline & \multicolumn{3}{|c|}{ Air } & \multicolumn{3}{|c|}{ Water } & \multicolumn{3}{|c|}{ Freezing-Thawing } & \multicolumn{2}{|c|}{ Salt Immersion } & \multicolumn{2}{|c|}{ Laitance Removal } \\
\hline & Ceramic & Porcelain & Polished & Ceramic & Porcelain & Polished & Ceramic & Porcelain & Polished & Before & After & Before & After \\
\hline \multirow{3}{*}{$\mathrm{DM}$} & 0.64 & 0.49 & 0.39 & 1.15 & 0.93 & 0.91 & 0.74 & 0.66 & 0.63 & 0.63 & 0.28 & 0.53 & 0.70 \\
\hline & 0.68 & 0.51 & 0.41 & 1.24 & 1.00 & 0.98 & 0.94 & 0.76 & 0.72 & 0.64 & 0.32 & 0.56 & 0.78 \\
\hline & 0.70 & 0.51 & 0.42 & 1.29 & 1.11 & 1.00 & 1.16 & 0.84 & 0.85 & 0.67 & 0.35 & 0.60 & 1.88 \\
\hline \multirow{3}{*}{$\mathrm{AM}$} & 0.78 & 0.63 & 0.51 & 1.53 & 1.45 & 1.51 & 1.36 & 1.14 & 1.08 & 0.92 & 0.69 & 0.69 & 0.98 \\
\hline & 0.82 & 0.64 & 0.51 & 1.60 & 1.51 & 1.57 & 1.37 & 1.25 & 1.24 & 0.93 & 0.70 & 0.74 & 1.02 \\
\hline & 0.97 & 0.67 & 0.56 & 1.63 & 1.71 & 1.58 & 1.43 & 1.46 & 1.27 & 0.93 & 0.73 & 0.78 & 1.06 \\
\hline \multirow{3}{*}{ ERM } & 1.21 & 0.99 & 0.97 & 1.04 & 0.93 & 0.89 & 0.62 & 0.46 & 0.45 & 1.57 & 1.24 & 1.07 & 1.27 \\
\hline & 1.23 & 1.03 & 0.97 & 1.08 & 0.93 & 0.91 & 0.63 & 0.50 & 0.51 & 1.58 & 1.30 & 1.09 & 1.29 \\
\hline & 1.27 & 1.07 & 0.99 & 1.10 & 0.98 & 0.95 & 0.69 & 0.59 & 0.58 & 1.61 & 1.40 & 1.14 & 1.34 \\
\hline
\end{tabular}




\section{Conclusions}

The adhesion performance of tiles with the injected epoxy resin adhesive was evaluated and the following conclusions drawn:

(1) As a result, in the case of using an epoxy resin adhesive within the scope of this study, the adhesive strength improved up to about two times compared to that of using the existing dry cement mortar under the air curing condition. However, it was confirmed that the adhesion strength decreased by up to about $30 \%$ compared to using dry cement mortar under water curing and freeze-thaw conditions. Meanwhile, in salt immersion and laitance conditions, it showed about four and two times higher adhesion strength than dry cement mortar, respectively.

(2) The workability and permeability of the epoxy resin adhesive were enhanced at a solvent mixing ratio of $0.5 \mathrm{wt} \%$. It is believed that this epoxy adhesive not only penetrated the interfaces of the tiles, mortar, and concrete, but also the mortar itself, thus improving the mechanical adhesion between each interface. This characteristic is potentially effective in improving the adhesion performance of porcelain and polished tiles with small pores, which make it difficult for the mortar to penetrate and mechanically adhere to the tiles.

(3) In addition to the improved mechanical adhesion between the tiles and mortar, the epoxy resin reinforcement also minimized the deterioration of adhesion due to shear stress by reducing the moisture evaporation and drying shrinkage of the mortar, which consequently reduced the shrinkage of the tiles themselves. In particular, the epoxy resin was expected to improve the adhesion performance of the large-sized tiles that are currently in demand because these tiles experience greater shear stress from shrinkage.

(4) The vulnerability of epoxy to moisture was observed under water and freeze-thaw curing conditions. However, based on the evaluation of the adhesion performance after standard air curing and salt immersion, the adhesion performance should be maintained if a stable level of performance is achieved by adequate air curing prior to exposure to harsh environments. However, further investigation of the effect of long-term exposure to harsh environments on the durability is required.

Author Contributions: Conceptualization, S.L. (Sangkyu Lee), S.L. (Sangyun Lee) and G.K.; Methodology, S.L. (Sangkyu Lee), S.L. (Sangyun Lee) and M.S.; Validation, S.L. (Sangkyu Lee), S.L. (Sangyun Lee), G.K., M.S., G.C., J.L. and J.N.; Formal analysis, S.L. (Sangkyu Lee) and G.K.; Investigation, S.L. (Sangyun Lee) and G.K.; Resources, S.L. (Sangkyu Lee) and S.L. (Sangyun Lee); Data curation, S.L. (Sangkyu Lee), S.L. (Sangyun Lee), M.S.; Writing - original draft preparation, S.L. (Sangkyu Lee), S.L. (Sangyun Lee), G.K. and M.S.; Writing-review and editing, S.L. (Sangkyu Lee), S.L. (Sangyun Lee), G.K., G.C. and J.L.; Visualization, S.L. (Sangkyu Lee), S.L. (Sangyun Lee) and G.K.; Supervision, G.K.; Project administration, S.L. (Sangyun Lee) and G.K.; Funding acquisition, S.L. (Sangyun Lee) and G.K. All authors have read and agreed to the published version of the manuscript.

Funding: This work was supported by the Korea Agency for Infrastructure Technology Advancement (KAIA) grant funded by the Ministry of Land, Infrastructure and Transport (Grant 20SCIP-B146646-03).

Conflicts of Interest: The authors declare no conflict of interest.

\section{References}

1. Carasek, H.; Cascudo, O.; Scartezini, L.M. Importância Do Materiais Na Aderência Os Revestimentos de Argamassa. In IV Simpoósio Brasileiro de Tecnoloia das Argamassas; Associação Nacional de Tecnologia do Ambiente Construído: Porto Alegre, Brazil, 2001; pp. 43-67.

2. Almeida, A.E.F.d.S.; Sichieri, E.P. Experimental Study on Polymer-Modified Mortars with Silica Fume Applied to Fix Porcelain Tile. Build. Environ. 2007, 42, 2645-2650. [CrossRef]

3. Sánchez, E.; Ibáñez, M.J.; García-Ten, J.; Quereda, M.F.; Hutchings, I.M.; Xu, Y.M. Porcelain Tile Microstructure: Implications for Polished Tile Properties. J. Eur. Ceram. Soc. 2006, 26, 2533-2540. [CrossRef]

4. Carty, W.M.; Senapati, U. Porcelain-Raw Materials, Processing, Phase Evolution, and Mechanical Behavior. J. Am. Ceram. Soc. 1998, 81, 3-20. [CrossRef] 
5. Mansur, A.A.P.; Santos, D.B.; Mansur, H.S. A Microstructural Approach to Adherence Mechanism of Poly (Vinyl Alcohol) Modified Cement Systems to Ceramic Tiles. Cem. Concr. Res. 2007, 37, 270-282. [CrossRef]

6. Inspect of the Government Offices Data; The National Assembly of the Republic of Korea Land Infrastructure \& Transport Committee: Seoul, Korea, 2018.

7. Mansur, A.A.P.; Nascimento, O.A.; Mansur, H.S. Data Collection of Five Years of Exterior Facade Pathologies in Brazil. In Proceedings of the QUALICER 2006: IX World Congress on Ceramic Tile Quality, Castellón, Spain, 12-15 February 2006; Volume 2, pp. 107-120.

8. Silvestre, J.D.; de Brito, J. Ceramic Tiling Inspection System. Constr. Build. Mater. 2009, 23, 653-668. [CrossRef]

9. Wetzel, A.; Zurbriggen, R.; Herwegh, M. Spatially Resolved Evolution of Adhesion Properties of Large Porcelain Tiles. Cem. Concr. Compos. 2010, 32, 327-388. [CrossRef]

10. Wetzel, A.; Herwegh, M.; Zurbriggen, R.; Winnefeld, F. Influence of Shrinkage and Water Transport Mechanisms on Microstructure and Crack Formation of Tile Adhesive Mortars. Cem. Concr. Res. 2012, 42, 39-50. [CrossRef]

11. Ohama, Y.; Demura, K.; Endo, T. Properties of Polymer-Modified Mortars Using Epoxy Resin Without Hardener. ASTM Int. 1993, 1176, 90-103.

12. Ohama, Y.; Demura, K.; Katsuhata, T. Investigation of Microcracks Self-Repair Function of Polymer-Modified Mortars Using Epoxy Resins without Hardener. In Proceedings of the 10th International Congress on Polymers in Concrete (CD-ROM); Fowler, D.W., DePuy, G.W., Murray, M.A., Eds.; The University of Texas at Austin: Austin, TX, USA, 2001.

13. Jenni, A.; Holzer, L.; Zurbriggen, R.; Herwegh, M. Influence of polymers on microstructure and adhesive strength of cementitious tile adhesive mortars. Cem. Concr. Res. 2005, 35, 35-50. [CrossRef]

14. Zheng, Z.; Li, Y.; Ma, X.; Zhu, X.; Li, S. High density and high strength cement-based mortar by modification with epoxy resin emulsion. Constr. Build. Mater. 2019, 197, 319-330. [CrossRef]

15. Herold, H. Fixing of stoneware "porcelanic" tiles by means of ceramic tile adhesives modified with redispersible polymer powder. In Proceedings of the World Congress on Ceramic Tile Quality, Castellón, Spain, 3-6 March 2000; pp. 77-88.

16. Jenni, A.; Herwegh, M.; Zurbriggen, R.; Aberle, T.; Holzer, L. Quantitative Microstructure Analysis of Polymer-Modified Mortars. J. Microsc. 2003, 212, 186-196. [CrossRef] [PubMed]

17. Yeon, J. Deformability of Bisphenol A-Type Epoxy Resin-Based Polymer Concrete with Different Hardeners and Fillers. J. Appl. Sci. 2020, 10, 1336. [CrossRef]

18. Bijen, J.; Schlangen, E.; Salet, T. Modelling of Effects of Shrinkage on the Performance of Adhesives. In Second International RILEM Symposium on Adhesion between Polymers and Concrete; RILEM Publications SARL: Dresden, Germany, 1999; pp. 299-310.

19. Rottstegge, J.; Arnold, M.; Herschke, L.; Glasser, G.; Wilhelm, M.; Spiess, H.W.; Hergeth, W.D. Solid state NMR and LVSEM studies on the hardening of latex modified tile mortar systems. Cem. Concr. Res. 2005, 35, 2233-2243. [CrossRef]

20. Gretz, M.; Plank, J. An ESEM investigation of latex film formation in cement pore solution. Cem. Concr. Res. 2011, 41, 184-190. [CrossRef]

21. Sugiman, S.; Salman, S.; Maryudi, M. Effects of Volume Fraction on Water Uptake and Tensile Properties of Epoxy Filled with Inorganic Fillers Having Different Reactivity to Water. Mater. Today Commun. 2020, 101360. [CrossRef]

22. Li, X.; Chen, M.; Zhang, J.; Gao, Q.; Zhang, S.; Li, J. Physico-Chemical Properties of Soybean Meal-Based Adhesives Reinforced by Ethylene Glycol Diglycidyl Ether and Modified Nanocrystalline Cellulose. Polymers 2017, 9, 463. [CrossRef] [PubMed]

23. Sugiman, S.; Putra, I.K.P.; Setyawan, P.D. Effects of the Media and Ageing Condition on the Tensile Properties and Fracture Toughness of Epoxy Resin. Polym. Degrad. Stab. 2016, 134, 311-321. [CrossRef]

Publisher's Note: MDPI stays neutral with regard to jurisdictional claims in published maps and institutional affiliations. 